\title{
JOGO SUPERAVES: POPULARIZANDO A CIÊNCIA E PROMOVENDO A SENSIBILIZAÇÃO AMBIENTAL
}

\author{
Luis Francisco Oliveira Pereira Gonzaga ${ }^{1}$ \\ Michell Pedruzzi Mendes Araújo² \\ Viviana Borges Corte ${ }^{3}$
}

Resumo: O presente artigo traz à tona um jogo de cartas colecionáveis como estratégia para promoção da popularização da ciência e sensibilização ambiental para diversos públicos. Foram catalogadas 112 espécies de aves dentro do Campus de Goiabeiras da Universidade Federal do Espírito Santo e os dados provenientes desse catálogo deram origem a um jogo didático nomeado "SuperAves". Durante o desenvolvimento dessa pesquisa foram realizadas oficinas de observação de aves e posteriormente o instrumento didático "Jogo SuperAves" foi utilizado em grupos focais. Como resultado, destacamos a necessidade de produção de mais materiais didáticos que promovam a popularização da ciência e a sensibilização ambiental.

Palavras-chave: Jogos; Ensino; Aves; Parques; Sensibilização Ambiental.

Abstract: This article brings up a collectible card game as a strategy to promote the popularization of science and environmental awareness for different audiences. 112 species of birds were cataloged within the Goiabeiras Campus of the Federal University of Espírito Santo and the data from this catalog, gave rise to a didactic game called "SuperAves", which has collectible cards. During the development of this research, birdwatching workshops were held and later the didactic instrument "Jogo SuperAves" was used in focus groups. As a result, we highlight the need to produce more teaching materials that promote the popularization of science and environmental awareness.

Keywords: Games; Teaching; Birds; Parks; Environmental Awareness.

\footnotetext{
1 Universidade Federal do Espírito Santo. E-mail: luispof@gmail.com, Link para o Lattes: http://lattes.cnpq.br/8236245970045784

2 Universidade Federal de Goiás. E-mail: michellpedruzzi@ufg.br.

Link para o Lattes: http://lattes.cnpq.br/6141634183456644

3 Universidade Federal do Espírito Santo. E-mail: viviana.borges@gmail.com.

Link para o Lattes: http://lattes.cnpq.br/3694434981958328
} 


\section{Introdução}

A forma como o ensino de ciências vem sendo tradicionalmente trabalhado nas escolas limita-o, em sua maior parte, a um processo de memorização de vocábulos, de sistemas classificatórios e de fórmulas pelos alunos, de modo que os estudantes apesar de aprenderem os termos científicos, não se tornam capazes de apreender e se apropriar do significado de sua linguagem (SANTOS, 2007). O ensino de ecologia, por exemplo, como ciência complexa que é, aparece, muitas vezes, como de difícil compreensão (GOMES; FRIEDRICH, 2001), assim como o ensino de Zoologia (seja em uma abordagem evolucionista, comportamental e/ou morfofisiológica), que tem sido ancorado no modelo tradicional, de forma bastante fragmentada e descontextualizada (PEREIRA, 2012).

Diante desse cenário, compreende-se que a proposta de ensino vertical se encontra na contramão do mundo contemporâneo e das habilidades e competências exigidas por uma sociedade cada vez mais líquida, multicultural, globalizada e digital. Destarte, esta estrutura educacional secular e rígida não é capaz de desenvolver as competências e habilidades necessárias para formar cidadãos críticos, autônomos, reflexivos e cientes do seu papel perante o meio ambiente (DIESEL et al., 2017).

Percebendo-se a contradição vivida pelo modelo de escola vigente na sociedade do século XXI, somos levados a refletir: Como fazer então para ensinar o conteúdo e, ao mesmo tempo, desenvolver habilidades e competências do século XXI? Como abordar o ensino de ciências para atender a demanda da sociedade moderna?

É consenso que os alunos devem ser estimulados a aprender e a quererem participar ativamente deste aprendizado. Para estimular o interesse dos alunos, recursos e metodologias inovadoras e que despertem o gosto pela ciência são necessários.

Portanto, novas metodologias de ensino- como o ensino por investigação, as metodologias ativas e a aprendizagem criativa - vêm ganhando destaque. Nessa corrente, visando preparar os alunos para exercerem o seu devido papel na sociedade, destaca-se um dos grandes desafios atuais na educação que é a transição de uma Tendência Tradicional (TT) para a Tendência Liberal Renovada Progressivista (TLRP) como proposta educacional que supera a instrução centrada no dizer do professor e na passividade do aluno.

É na perspectiva da TLRP, em que a ideia de aprender fazendo está sempre presente e valoriza as tentativas experimentais, a pesquisa, a descoberta, o estudo do meio natural e social e, o método de solução de problemas (LUCKESI, 2005), que se dá a possibilidade do deslocamento do foco do docente- ensino- para o estudante- aprendizagem-. A ideia é corroborada por Freire (1996), ao referir-se à educação como um processo que se realiza na interação entre sujeitos históricos por meio de suas palavras, 
ações e reflexões. Com base nessa ideia, é possível inferir que, enquanto o método conteudista prioriza a transmissão de informações e tem sua centralidade na figura do docente, no método ativo, os estudantes ocupam o centro das ações educativas e o conhecimento é construído de forma autônoma e colaborativa. Assim, as metodologias ativas procuram criar situações de aprendizagem em que os aprendizes elaboram materiais didáticos, assentam conhecimentos em ação, pensam e conceituam o que desenvolvem, constroem conhecimentos sobre os conteúdos envolvidos nas atividades que realizam, bem como desenvolvem estratégias cognitivas, críticas e reflexivas sobre suas práticas, e exploram atitudes e valores pessoais e sociais.

Concernentemente a tais metodologias, a aprendizagem criativa destaca a importância de considerarmos os 4Ps: projetos, parcerias, paixão e pensar como estratégia para ensinar conteúdos brincando (RESNICK, 2014). Eles podem ser usados como estratégia envolvente para trabalhar com temas e conteúdos do currículo de Ciências e Biologia de forma motivadora e instigante. Esses quatro pilares oferecem possibilidades para criar, testar, errar e construir conhecimento em situações reais de aprendizagem e de forma ativa sobre problemas e temáticas sociais.

Dentro do escopo das premissas apresentadas, destacamos, como forma de promoção da ludicidade e estímulo do interesse dos alunos, estratégias como aprendizagem por meio de jogos (Game Based Learning GBL) e aprendizagem em equipe (Team-Based Learning - TBL) (DIESEL et al., 2017).

A adoção de tais procedimentos e abordagens demanda reconsiderar o currículo, as metodologias de ensino e aprendizagem, o papel docente e os espaços de aprendizagem (DIESEL et al., 2017).

Dentre estas metodologias alternativas, os jogos são relevantes alternativas para se conseguir, com êxito, a atenção e a participação dos alunos. A integração de assuntos promovida pelos jogos leva a contextos reflexivos que promovem ações transformadoras (CANDIDO, 2012). Jogo seria qualquer atividade em que exista a figura do jogador praticante, individual ou em conjunto, e regras que podem ser para ambiente restrito (como xadrez) ou livre (como um faz de conta) (KISHIMOTO, 2017).

Segundo Fortuna (2003, p. 28), "enquanto jogamos, desenvolvemos iniciativa, imaginação, raciocínio, memória, atenção, curiosidade e interesse, concentrando-se por longo tempo em uma atividade". Portanto, a utilização de jogos pode preencher muitas lacunas expostas pelo processo de transmissão de conhecimentos. Jogar permite que a criança constitua o mundo ao seu redor, assimile experiências e informações e, sobretudo, incorpore atitudes e valores (CUNHA, 1988), de maneira que os benefícios do uso de jogos podem se estender a estudantes em contexto escolar, visitantes de espaços não formais de educação, turistas e a comunidade em geral. 
Alguns estudos como os de Siqueira e Antunes (2013); Calisto, Barbosa e Silva (2012); Patriarcha-Graciolli, Zanon e Souza (2008); Ferreira e Utsumi (2016); Malaquias et al. (2012) têm trazido à tona a relevância de se trabalhar com jogos didáticos para possibilitar a educação ambiental. Essas pesquisas reverberaram durante a criação de um jogo de cartas colecionáveis que abordam, dentre outras características, o grau de conservação de cada espécie de ave. Dessa forma, os jogadores terão acesso a informações que os levem a refletir sobre a necessidade emergente de buscar estratégias para conservação da biodiversidade do planeta Terra.

De acordo com Norman e Severiano (2018, p. 43), "utilizar conhecimentos relacionados às aves pode auxiliar no processo de conscientização ambiental da comunidade, tornando mais eficaz a Educação Ambiental formal e informal'. Costa (2007), de forma análoga, defende a utilização de conteúdos sobre aves como ferramenta didática, haja vista que possibilita ao educando um estímulo, aumentando sua concentração, como também o reconhecimento do meio que o cerca.

Tendo como base o que foi mencionado, o presente trabalho apresenta como proposta a criação de um jogo de cartas colecionáveis como estratégia promissora para a promoção da popularização de conhecimentos científicos para diversos públicos e da educação ambiental. O potencial de uso educacional deste tipo de material é extremamente amplo, podendo alcançar diversas idades e setores da sociedade. De forma específica, o presente trabalho objetivou: inventariar as aves presentes no campus goiabeiras da Ufes; propor a criação de um jogo de cartas como ferramenta para divulgação e aprendizado de Biologia da conservação e promoção da sensibilização ambiental; demonstrar que as cartas colecionáveis podem gerar conhecimento científico para a população; estimular a prática de atividades de ciência cidadã como o birdwatching, estimular a produção de materiais direcionados à popularização da ciência e à educação ambiental.

\section{Produtos de popularização da ciência como souvenires em espaços não formais de Educação Científica}

A maioria das nações do mundo, preocupadas com a conservação e manejo dos seus ecossistemas nativos e das espécies que neles habitam, vem estabelecendo medidas legais para proteger ou regular o uso da terra em seus territórios. Dentre os principais instrumentos regulatórios encontram-se as unidades de conservação ou áreas protegidas (FONSECA et al., 1997). A expansão do número de áreas protegidas no mundo foi considerada uma estratégia particularmente vital para a conservação dos recursos naturais do planeta a partir do III Congresso Mundial de Parques, realizado em Bali em 1982 (SOUZA, 2013).

$\mathrm{Na}$ atualidade, o Brasil possui um extenso sistema de unidades de conservação. São 2201 unidades de conservação, das quais 2180 são continentais e 81 são marinhas. 998 UCs federais, 908 UCs estaduais e 295 
UCs municipais, em todas as 12 categorias de manejo, totalizando mais de 250 milhões de hectares de áreas continental e marinha protegidas (BRASIL, 2019).

Apesar destes números, há fragilidade no sistema de unidades de conservação, e esta não se restringe somente à sua má distribuição geográfica e ecológica, como apontaram Ayres et al. (1997). Dentre os principais problemas encontram-se a situação fundiária indefinida de várias unidades, instabilidade política das agências de meio ambiente, conflito entre comunidades locais e indígenas em algumas dessas áreas, tanto dentro quanto ao redor dos seus limites, além de falta de pessoal e recursos financeiros, limitando seriamente o manejo das áreas protegidas (FONSECA et al., 1997; ARRUDA, 1997; GALETTI, 2001).

Alguns parques brasileiros, tanto nacionais quanto estaduais ou municipais, têm se mostrado bastante importantes no contexto regional, principalmente onde o turismo é uma das principais atividades econômicas. Atuando na economia local podem gerar dezenas de empregos diretos e indiretos (funcionários, fiscais, monitores ambientais, pousadas, campings, alimentação e artesanato) com repasse de recursos da arrecadação para o município e importante receita de ICMS Ecológico. O encerramento dessas atividades, a pretexto de melhorar as condições para a manutenção da biodiversidade local, seria certamente inviável econômica, política e socialmente (FONSECA, 1999). Pesquisas destacam como o turismo gera renda significativa para os parques e para as comunidades no entorno, direta e indiretamente, com guias, hospedagens, lojas, produtos, restaurantes, pacotes de viagens e outros (LOVEJOY, 2006; MAYER, 2010).

De maneira mais específica, Litirell (1994) aponta qual é o tipo ideal de souvenir para cada tipo de turista e, segundo a autora, os turistas de parques naturais se interessam mais por produtos colecionáveis, cartões postais, livros sobre a área, materiais impressos e informações sobre animais endêmicos, o que faz com que um álbum de cartas colecionáveis seja um produto ideal para esse tipo de público.

\section{Produtos de popularização da ciência para estudantes}

Entende-se que a utilização das cartas colecionáveis do jogo Superaves não deve ficar restrita ao uso nos parques, e sim usadas também de maneira direta no ensino de ciências, biologia e/ou educação ambiental na educação básica. Parafraseando Pádua et al. (2003), entendemos que os conhecimentos sobre aves associados à Educação Ambiental podem mostrar aos alunos que eles estão envolvidos na ação de conservação, independentemente da faixa etária, havendo uma conscientização em relação à proteção de todo o meio ambiente.

Cada pessoa possui competências e habilidades diferentes umas das outras, portanto nem todos absorvem conhecimento da mesma forma, de 
acordo com a teoria das múltiplas inteligências de Gardner (1993). Compete ao educador descobrir e utilizar diferentes alternativas para promover e estimular o desenvolvimento e o aprendizado efetivo dos vários e diferentes alunos de cada turma, para que assim as aulas não fiquem restritas à mera exposição de conteúdos - aulas tradicionais. Este método de ensino vertical de transmissão do conhecimento do professor para o aluno culmina em uma aprendizagem que se processa de forma mecânica, em que não é permitido o desenvolvimento do pensamento independente e criativo (NEVES et al., 2010).

Usualmente, o ensino é focado no modelo tradicional, em que o docente explica o conteúdo verbalmente e espera que os alunos memorizem o que foi dito e reproduzam nas avaliações (HOBSBAUM et al., 1996; STOFFLETT, 1999; RESCHKE, 2009). É, na verdade, imprescindível que o ensino seja permeado por atividades motivadoras como aulas de campo, aulas de laboratório, debates, mesas redondas, vídeos, jogos etc.

Ao reconhecermos as dificuldades em ensinar conteúdos de ciências no ensino fundamental e médio, é necessário pensar em formas de contribuir para os processos de ensino e aprendizagem nestes níveis de ensino (KISHIMOTO, 2017).

Os alunos devem ser estimulados a aprender e a quererem participar ativamente deste aprendizado. Para estimular o interesse dos alunos, recursos e metodologias inovadoras, como os jogos, são sempre necessários. Outrossim, a integração de assuntos promovida por eles leva a contextos reflexivos que promovem ações transformadoras (CANDIDO, 2012).

\section{Materiais e métodos}

\section{Área de Estudo}

Esse estudo foi desenvolvido na Universidade Federal do Espírito Santo- Ufes, que foi fundada em 5 de maio de 1954. Possui quatro campi universitários - em Goiabeiras e Maruípe, na capital; e nos municípios de Alegre, no sul do Estado; e São Mateus, no norte capixaba - com uma área territorial total de 4,3 milhões de metros quadrados.

Goiabeiras é o principal campus da Ufes. Localizado na Capital do Espírito Santo, Vitória, concentra a maior parte dos cursos de graduação, mestrado e doutorado. O campus, é cercado por uma área de manguezal, vegetação de transição, e vegetação de afloramentos rochosos, todas mantidas sob proteção ambiental.

\section{Coleta de dados}

Para inventariar a avifauna do campus, foram demarcadas seis trilhas dentro dos limites do campus (Figura 1), com extensão de: Trilha I- $1.353 \mathrm{~m}$, trilha II- $1.094 \mathrm{~m}$, trilha III- $1.323 \mathrm{~m}$, trilha IV- $1.127 \mathrm{~m}$, trilha V- $868 \mathrm{~m}$, trilha VI$1.199 \mathrm{~m}$, que foram percorridas por 12 meses (2018) com idas semanais (48 
excursões), com duração média de 4 horas cada (entre 5:30h e 9:30h), e os resultados foram plotados num gráfico de curva de acumulação de espécies. Além disso, utilizamos literaturas auxiliares como Ribeiro (2011) e Costa (2006).

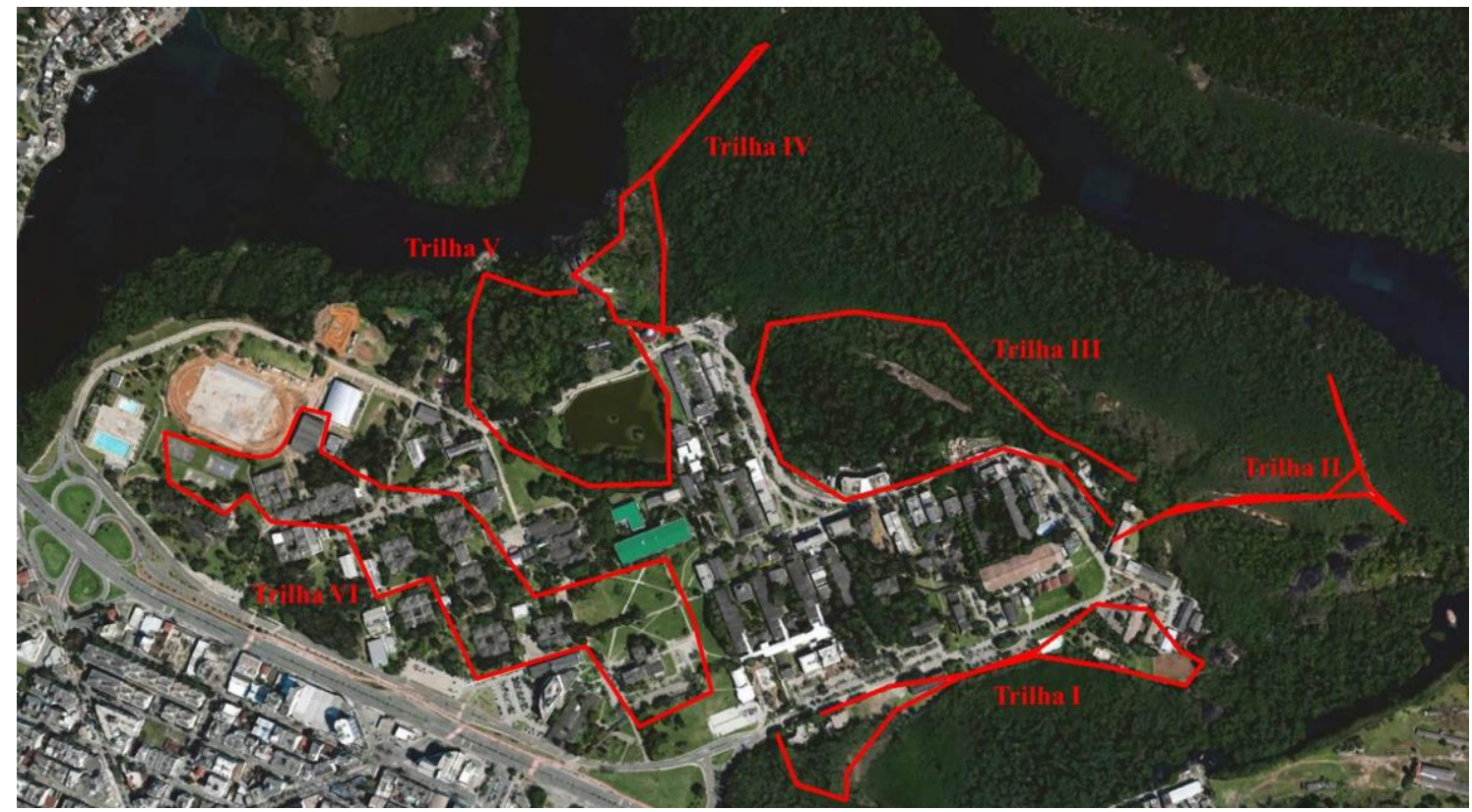

Figura 1: Trilhas utilizadas no levantamento de avifauna do Campus de Goiabeiras da Universidade Federal do Espírito Santo.

Fonte: Google Maps com edições dos autores

\section{Criação do jogo}

Foram escolhidas 81 espécies de aves para compor o jogo. Cada espécie está representada em uma carta. Cada carta apresenta a imagem da ave e informações tais como: o nome popular; o nome científico como consta na Lista de Aves do Brasil do Comitê Brasileiro de Registros Ornitológicos (CBRO) (PIACENTINI, 2015); tamanho; peso; grau de conservação; ocorrência no Brasil; número de ovos por ninhada e uma curiosidade sobre a espécie (Wikiaves, Aves de Rapina Brasil (MENQ, 2019), Handbook of the Birds of the World (DEL HOYO, 2019, Encyclopedia of Life, IUCN Red List of Threatened Species e Animal Diversity Web). Com exceção da curiosidade, cada uma das informações está escrita em português e em inglês (Figura 2). Ademais, há duas cartas instrutivas, uma com as regras do jogo e outra explicando o significado de cada elemento do jogo. 

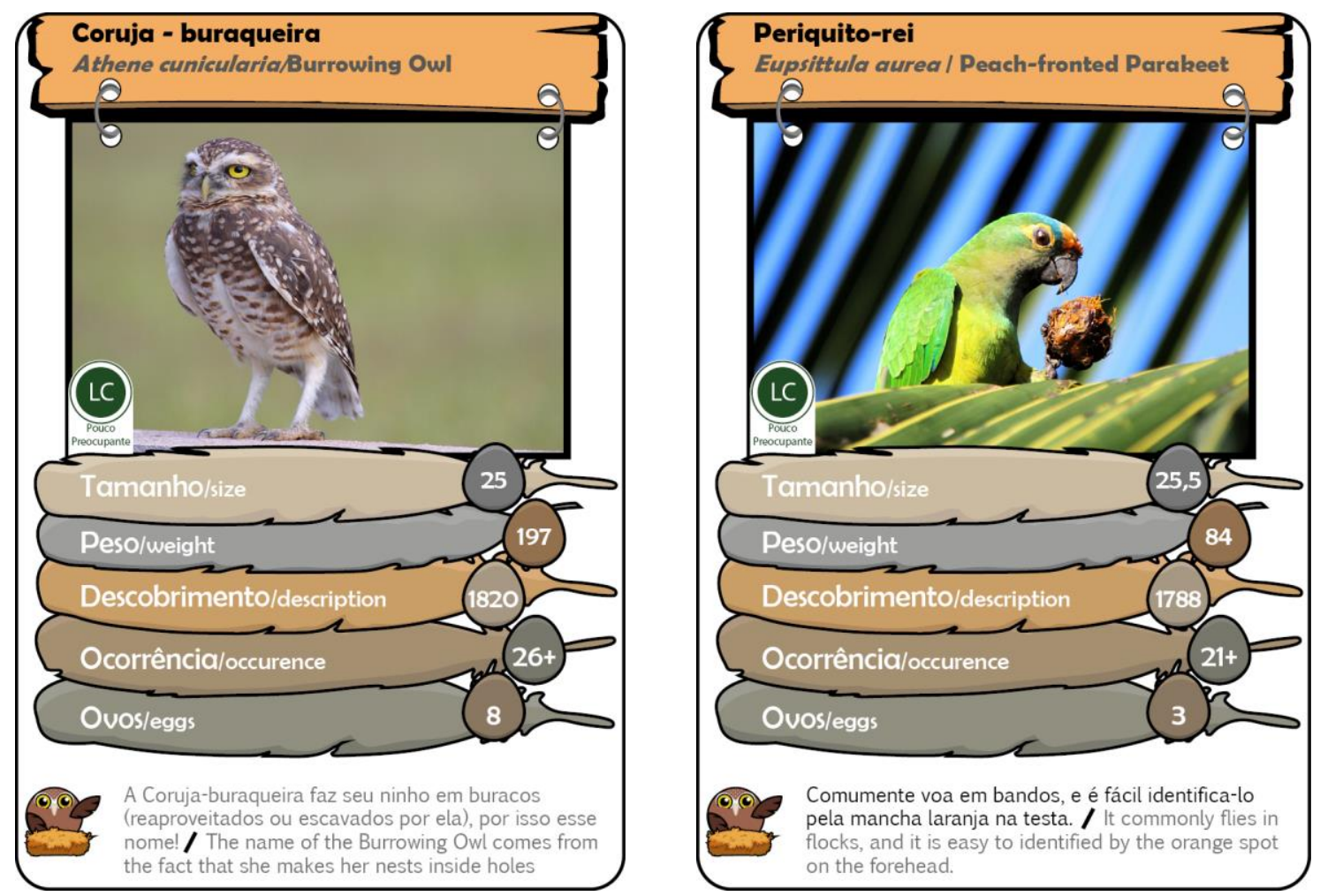

Figura 2: Representação de cartas do jogo SuperAves.

Fonte: Acervo dos autores.

\section{Regras do jogo}

O funcionamento do jogo de cartas se baseia no jogo Super Trunfo $\AA$, da empresa Grow $\AA^{\circledR}$, em que as cartas são divididas em grupos ( $A, B, C$ e $\left.D\right)$, e cada uma delas tem características com valores atribuídos. Ao iniciar o jogo as cartas são embaralhadas e colocadas em um monte. Os jogadores selecionarão uma carta no topo do monte por rodada. Ao sacar a carta, o jogador escolhe a característica, e a carta com o maior valor daquela característica vence, e assim o vencedor daquela rodada recebe as cartas dos outros jogadores. $\mathrm{O}$ jogo prossegue assim até que as cartas acabem e o jogador que obtiver a maioria das cartas vence. Também estará presente uma carta especial "superave", que quando em jogo, é superior a todas as outras, apenas perdendo para alguma que for do mesmo grupo (ex.: carta especial do grupo A ganha de todos os grupos, menos do grupo A).

\section{Pesquisa com alunos}

Foram selecionados três grupos focais de 15 alunos cada, do Ensino Médio da rede pública para utilização do jogo. Foram gravados os relatos dos alunos, sobre as impressões que tiveram do jogo. Em seguida os alunos foram submetidos a algumas perguntas: "E então, o que acharam do jogo?", "Se 
sentiram interessados ou curiosos com alguma das aves?", "O que acharam das fotos das aves, das características escolhidas e das curiosidades?", "E sobre o material utilizado?", "Teriam alguma outra sugestão para melhorar o jogo?".

\section{Pesquisa com gestores de Unidades de Conservação (UC's)}

Foram selecionadas sete Unidades de Conservação (Parques nacionais, estaduais e municipais) as quais levar o jogo para avaliação e entrevista com os gestores das unidades de conservação. Após serem apresentados ao jogo, responderiam as seguintes perguntas sobre as impressões que eles tiveram do jogo:

"E então, o que acharam do jogo?", "O que acharam das fotos das aves, das características escolhidas e das curiosidades?", "E sobre o material utilizado?", "Teriam alguma outra sugestão para melhorar o jogo?", "O que vocês achariam de um jogo desse tipo na unidade de conservação na qual eles você atua?", "Acha que seria interessante a existência de lojas com material a ser vendido que possuísse relação com a UC?".

\section{Resultados}

\section{Inventário de Aves}

Com base na metodologia utilizada, 112 espécies de aves tiveram sua ocorrência confirmada, distribuídas dentro de 38 famílias e 16 ordens. Dessas, 110 espécies possuem o status de conservação definido como "Pouco Preocupante", e duas delas (Conirostrum bicolor e Primolius maracana) possuem o status de "Quase Ameaçada".

Jogo

O jogo SuperAves se constituiu de 83 cartas, sendo destas, 80 cartas comuns com as espécies, uma carta SuperAve, uma carta contendo as regras do jogo, e uma carta explicando o que significa cada elemento contido na carta. $\mathrm{O}$ jogo completo encontra-se apresentado no Anexo I.

\section{Impressões e Relatos}

\section{Impressões dos discentes}

O jogo é apresentado aos alunos, bem como as cartas de instrução e, após lê-las, eles começam a jogar. Após algumas partidas foi feita a entrevista, e os relatos dos alunos estão descritos a seguir: 


\section{Pergunta 1- E então, o que acharam do jogo?}

\section{Respostas:}

TURMA 1 "Muito legal!", "Muito criativo!", "Ótimo", "Bem divertido!”;

TURMA 2 "Interessante", "Legal", "Melhor que o Uno®", "Muito bom", "Gostei, foi bom pra aprender", "Diferente";

TURMA 3 "Muito divertido!", "Interessante e gostei muito!", "Muito legal, diferente e inovador!", "Massa!"

\section{Pergunta 2 - Sentiram-se interessados ou curiosos com alguma das aves presentes no jogo?}

\section{Respostas:}

TURMA 1 "Sim.", "Não.", "Sim, a coloridinha!", "Observei mais as características do que as fotos.", "Não observei muito durante o jogo, mas agora depois, sim!";

TURMA 2 "Sim", "Achei algumas bem bonitas", "Pesquisaria depois", "Eu não pesquisaria";

TURMA 3 "Sim", "Sim as aves são super interessantes, e eu aprendi algumas coisas novas", "Não".

\section{Pergunta 3 - O que acharam das fotos das aves, das características escolhidas e das curiosidades?}

Respostas:

TURMA 1 "As fotos estão boas!", "Fotos bonitas!", "Estão boas e bem perto, dá pra ver bem as aves";

"Eu gostei de saber do peso!", "Eu achei legal saber quantos ovos!", "Eu achei meio repetida o grau de conservação e a ocorrência", "Podia tentar falar também do hábitat!", "Podia ter o número de indivíduos!";

"Sim", "Não", "Sim, eu li sobre o Gavião-carrapateiro, que se alimenta dos carrapatos dos bois"; "Ótimas";

TURMA 2 "Bem legais as fotos!", "Muito boas!", "Bem coloridas!",

"Não entendi sobre o grau de conservação", "Algumas características estavam vindo repetidas, como a ocorrência", "Seria legal ter a ocorrência delas na UFES", "Podia ter longevidade", "Seria legal saber se é predador ou se é presa";

"Sim tinha muita coisa que eu não sabia", "Nem sabia que na Ufes 
TURMA 3 "Achei muito bonitinhas as aves", "Achei que combinou bastante", "As fotos ficaram bem nítidas".

\section{Pergunta 4 - E sobre o material utilizado?}

\section{Respostas:}

TURMA 1 "Achei bom.", "Poderia ser mais resistente!" bom!"

TURMA 2 "Achei que é meio fácil de rasgar", "O design ficou muito

TURMA 3 "Gostamos do material", "Podia ser mais durinho", "Podia ser um pouco mais plastificado".

\section{Pergunta 5 - Teriam alguma outra sugestão para melhorar o jogo? Respostas:}

TURMA 1 "Usar melhor a numeração e o grupo", "Melhorar o critério de desempate".

TURMA 2 "Podia ter um mapa de ocorrência das aves na UFES", "Podia usar melhor os números e grupos", "Podia tirar os grupos".

TURMA 3 "Tirar o grau de conservação, porque temos que decorar o que é cada coisa, e achei meio confuso", "Melhorar o critério de desempate".

\section{Discussão}

A amostragem das espécies de aves presentes no Campus Goiabeiras da Ufes se deu até que a curva de acumulação de espécies alcançasse um patamar estável, de acordo com trabalhos pretéritos que utilizaram o mesmo campus como área de estudo para trabalhos envolvendo aves (RIBEIRO, 2011; COSTA, 2006), bem como dados de ocorrência de aves em sites especializados, como, por exemplo, na prática de observação de aves (birdwatching).

Talvez algumas espécies não tenham sido encontradas no presente trabalho, como Juruviara-boreal (Vireo olivaceus), Piolhinho (Phyllomyias fasciatus), Pomba-galega (Patagioenas cayennensis), Mariquita (Setophaga pitiayumi), Bentevizinho-de-penacho-vermelho (Myiozetetes similis), Juriti-pupu (Leptotila verreauxI), Anu-branco (Guira guira), Guaracava-de-barriga-amarela (Elaenia flavogaster), Rolinha-picui (Columbina picui), Pombo-doméstico (Columba livia), devido ao tempo passado entre um trabalho e outro, em que a avifauna presente apresentou leve alteração, e também devido ao fato de a UFES se manter sempre em expansão mesmo num espaço limitado e alguns prédios novos talvez terem sido construídos em locais de preferência para confecção de ninhos ou pouso de determinadas espécies. Como é elencado por Marini (2005), as principais ameaças para aves são fragmentação e perda 
de habitat, além de invasão de espécies exóticas, poluição, perturbação antrópica, morte acidental, alterações na dinâmica das espécies nativas, desastres naturais e perseguição.

O Campus de Goiabeiras da Ufes se apresenta como um local de grande potencial a para o estímulo ao birdwatching, uma vez que apresenta uma quantidade expressiva de espécies de aves, principalmente quando relacionada a sua área (o Campus Goiabeiras da Ufes possui aproximadamente $1 \%$ da área do município de Vitória, mas conta aproximadamente $45,7 \%$ das espécies de aves presentes no mesmo). O birdwatching além de trazer benefícios como a oportunidade de estar próximo à natureza, competição, esporte, participação de uma atividade social (KELLERT, 1985), fatores esses que geram bem-estar social e individual, também aproxima o cidadão de um local que lhe é pouco familiar, gerando assim empatia e um senso de pertencimento ao local, seja ele uma universidade, parque ou outro. Tal atividade constitui-se não apenas na prática de ciência cidadã, mas também uma importante ferramenta de divulgação científica. Entretanto, os esforços para tornar a UFES um local adequado a prática de birdwatching devem partir da própria universidade, aliada ao poder público e atores regionais (como birdwatchers, biólogos e ONGs).

Algumas das espécies de aves inventariadas não entraram no jogo por falta ou de informação, ou de uma fotografia com boa qualidade. A principal dificuldade encontrada durante a confecção do jogo foi inclusive a coleta de dados sobre as aves. Muitos dados básicos de história natural das mesmas encontram-se, em sua maioria, pulverizados em diversos livros ou em websites informais como blogs, que são criados e editados muitas vezes sem critério científico. Além disso, nos websites mais completos e mais cuidadosos se faz necessário pagar para obter acesso às informações. Durante a coleta de dados também pudemos observar que os sites que geralmente eram alimentados por informações advindas de um público leigo (ciência cidadã) possuíam mais informações e informações mais precisas. Como exemplo, podemos citar a distribuição geográfica da Saíra-amarela (Tangara cayana) nos websites Wikiaves, IUCN Red List e E-bird (Figura 3). Tanto o Wikiaves quanto o E-bird são alimentados com dados também de pessoas leigas, o que nos mostra a necessidade cada vez maior de aceitarmos a ciência cidadã (SULLIVAN, 2009) como fonte válida de conhecimento, sempre com o devido cuidado em filtrar e checar as informações, que devem ser também validadas pelo meio científico (SILVERTOWN, 2009). 


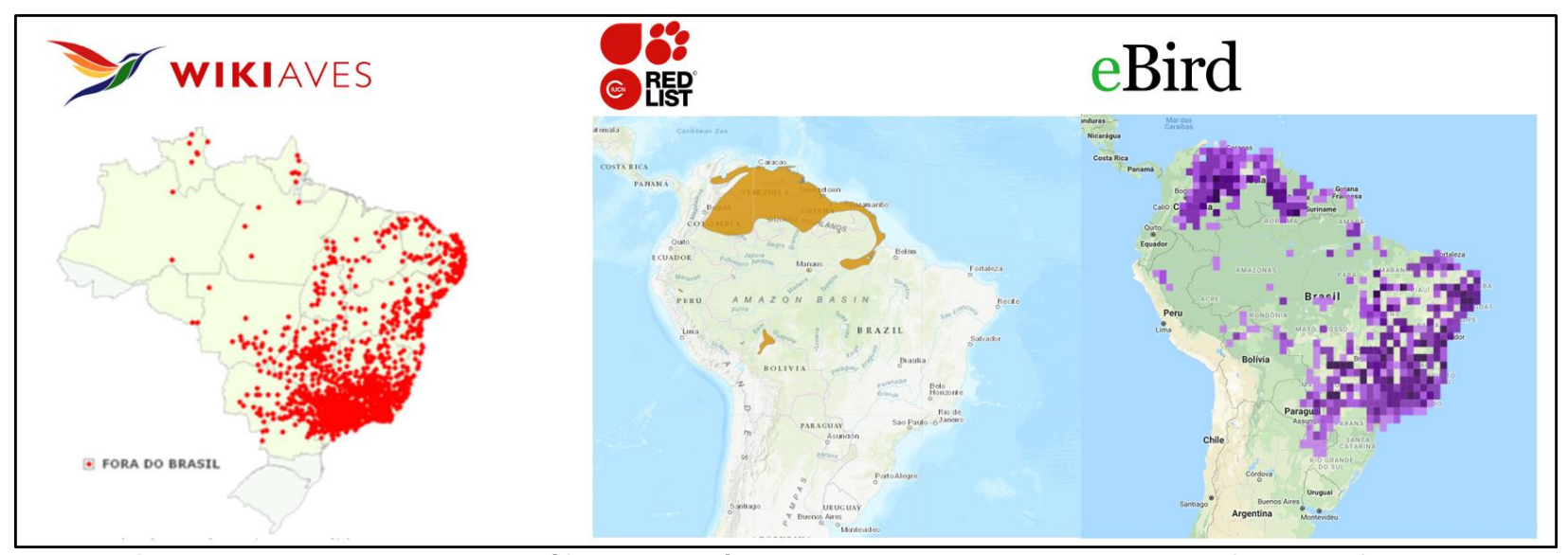

Figura 3: Distribuições geográficas atribuídas a Tangara cayana segundo diferentes fontes.

Fonte: Wikiaves, IUCN, e E-bird.

Além de contribuir com a ornitologia, a ciência cidadã atualmente participa de outros projetos como, por exemplo, mudanças climáticas, espécies invasoras biologia da conservação, restauração ecológica, monitoramento de qualidade de água, ecologia de populações e monitoramentos de todos os tipos (SILVERTOWN, 2009).

Ao apresentar o jogo aos alunos, percebe-se uma curiosidade natural pelo novo e pelo lúdico, e logo que eles se põem a jogar as dúvidas vão surgindo. Eles são estimulados a buscarem pelas respostas dentro do jogo (com as cartes de instrução) sendo as dúvidas respondidas por eles mesmos, num processo de autoaprendizagem e descobertas pessoais, que promovem por sua vez a aquisição do conhecimento de forma ativa e assim o aprendizado, de maneira prevista na proposta liberal renovada progressivista (BETTI, 2008, LUCKESI, 2005). No caso da persistência da dúvida, há uma explicação sobre a situação que gerou a dúvida.

Percebe-se que a jogabilidade é bastante fácil e fluída, pois quase todos os alunos compreendem e aplicam as regras do jogo sem questionarem ao aplicador como fazê-lo. Entretanto, no momento de empate e de uso da superave, alguns tornaram a perguntar como proceder. Além disso, logo os alunos percebem que a característica "Grau de Conservação" não se altera muito, e logo param de utilizá-la.

Durante a entrevista, todos os alunos relataram boas impressões sobre o jogo, dando um retorno positivo, classificando-o como "diferente, interessante e legal". Alguns disseram não ter se interessado muito pelas aves, e que não buscariam mais informações sobre ela, mas a maioria afirmou o contrário, que haviam se interessado, e que gostariam de buscar mais informações sobre biologia das aves. Por ter sido um momento não muito prolongado de contato dos alunos com o jogo, muitos focaram mais nas características apresentadas nas cartas (responsáveis por ganhar ou perder) que nas próprias aves. Todos gostaram das fotos, e se interessaram pelas curiosidades apresentadas, além de citar como característica a ser mudada o "Grau de Conservação". Alguns também comentaram sobre mudar "Ocorrência" e "Ovos". 
Em relação ao material utilizado, também foi consenso a necessidade de melhoria da sua resistência. Sugeriu-se mudar também o critério de desempate e a classificação dos grupos. Alguns alunos comentaram sobre as curiosidades de cada carta e também fizeram algumas perguntas como o motivo da cor de uma ave (Platalea ajaja), o fato de uma ave ter o status de conservação diferente das outras (Primolius maracana), por que motivos duas aves eram parecidas e tinham o nome parecido também (Mimus gilvus, e Mimus saturninus) e se algumas aves de cores parecidas eram aparentadas (Coereba flaveola e Pitangus sulphuratus), o que demonstra interesse em saber mais sobre as aves e suas características e sugere também a aquisição de algum conhecimento científico, uma vez que se espera que procurem por essas respostas posteriormente, e que isso se desdobre na busca por outras informações.

Uma potencialidade do jogo, demonstrada na pesquisa com grupos focais, são as fotos de boa resolução e qualidade, muitas das quais foram tiradas pelos próprios pesquisadores e/ou colaboradores. Isso evidencia que as imagens atraem a atenção de potenciais jogadores e/ou colecionadores para o jogo. Nesse caminho, parafraseando Espinosa (1996), entendemos que as imagens possuem um enorme potencial para transmitir determinados conceitos, muitas vezes com mais clareza que a linguagem verbal.

Não foi possível apresentar o jogo e realizar a entrevista com os gestores das unidades de conservação, como planejado inicialmente. Em alguns casos nem mesmo o contato foi possível, por conta de não atenderem os telefonemas ao parque, não responderem e-mails, ou por processos burocráticos do próprio órgão que regulamenta os parques. Entretanto, mesmo sem a coleta das impressões diretas dos gestores, podemos dizer que a presença de lojas dentro dos parques com produtos de divulgação dos conhecimentos científicos relacionados ao próprio parque gera receita, além de interesse e empatia pelas unidades conservação por parte da população (LITIRELL, 1994; LOVEJOY, 2006; MAYER, 2010).

\section{Considerações finais}

Percebemos, com o desenvolvimento dessa pesquisa, a necessidade de produção de mais materiais didáticos direcionados à popularização dos conhecimentos científicos e à sensibilização ambiental, sejam eles livros, sites, artigos, dentre outros, que atuem de maneira a reunir informações básicas, tanto na ornitologia quanto em outras áreas de conhecimento da biologia. Além disso, a própria ornitologia carece de pesquisas de história de vida das aves para trazer essas informações básicas (morfometria, reprodução, expectativa de vida, dieta, área de ocorrência, grau de conservação etc.).

Mister também se faz destacar que o birdwatching é uma prática cada vez mais consolidada em alguns países, porém ainda com muito espaço para crescer e com alto potencial eco turístico e econômico. Nesse ínterim, a 
Universidade Federal do Espírito Santo apresenta-se como espaço promissor para tal atividade.

O uso de jogos no ensino está cada vez mais presente, assim como práticas que estimulem a curiosidade, a autogestão, a experimentação, pesquisa e descoberta por parte dos próprios alunos, deslocando cada vez mais o professor do pedestal da exclusividade do conhecimento e o colocando como mediador da aprendizagem como prática educacional horizontal e de via dupla. Tal práxis torna-se imperativa, sobretudo, às disciplinas de Ciências e Biologia, no que tange aos conteúdos tangíveis ao conhecimento sobre o meio ambiente. Acreditamos que o aluno, ao envolver-se ativamente com o conteúdo ministrado, pode agir também ativamente na sociedade em prol de um melhor cuidado com o meio em que vive e em busca da sustentabilidade.

Os alunos estão ávidos por novas e estimulantes formas de aprendizado, e pela receptividade e interesse demonstrados por eles, o SuperAves tem tudo para, após algumas alterações e revisões, ser bem aceito e difundido. Fazem-se necessários mais testes com diferentes públicos-alvo, além de apresentar o jogo aos gestores das unidades de conservação a fim de termos um produto melhor, que atenda às necessidades dos diversos públicos e, principalmente, estreitem os laços entre o homem e a natureza.

\section{Referências}

ANIMAL DIVERSITY WEB, Museu de Zoologia, Universidade de Michigan. Disponível em: < https://animaldiversity.org/>. Acesso em: 12 jun. 2019.

ARRUDA, R. S. V. Traditional populations and the protection of the natural resources in conservation units. Anais do I Congresso Brasileiro de Unidades de Conservação, Conferências e Palestras. p. 351-367.1997.

AYRES, J. M. Abordagens inovadoras para conservação da biodiversidade do Brasil: os corredores ecológicos das florestas neotropicais do Brasil. Ministério do Meio Ambiente, 1997.

BETTI, M. Convergência e integração: uma proposta para a educação física de $5^{\text {a }}$ a $8^{\mathrm{a}}$ série do ensino fundamental. Revista brasileira de Educação Física e Esportes, São Paulo, v. 22, n. 1, p. 5-23, 2008.

BRASIL. Ministério do Meio Ambiente (MMA) Painel Unidades de Conservação. Disponível em: http://www.mma.gov.br/areasprotegidas/cadastro-nacional-de-ucs.html. Acesso em: 12 jun. 2019.

CALISTO, A.; BARBOSA, D.; SILVA, C. Uma Análise Comparativa entre Jogos Educativos Visando a Criação de um Jogo para Educação Ambiental. Anais do Brazilian Symposium on Computers in Education (Simpósio Brasileiro de Informática na Educação - SBIE), Disponível em: <https://brie.org/pub/index.php/sbie/article/view/1439>. Acesso em: 27 abr. 2020.

CANDIDO, C.; FERREIRA, J. de F.. Desenvolvimento de material didático na forma de um jogo para trabalhar com zoologia dos invertebrados em sala de aula. Cadernos da Pedagogia, São Carlos, v. 6, n. 11, p.22-33, jul. 2012.

Revista brasileira educação ambiental 
COSTA, M. A. S. de M. Composição de duas áreas verdes do município de Vitória, Espírito Santo. Trabalho de Conclusão de Curso (Bacharelado em Ciências Biológicas). Universidade Federal do Espírito Santo, Vitória, 2006.

COSTA, R. G. A. Observação de aves como ferramenta Didática para a Educação Ambiental. Revista Didática Sistêmica, v. 6, p. 33-44, jul./dez. 2007.

CUNHA, N. H. S. Brinquedo, desafio e descoberta: subsídios para a utilização e confecção de brinquedos. Rio de Janeiro: FAE. 1988.

DEL HOYO, J., ELLIOTT, A., SARGATAL, J., CHRISTIE, D.A. \& KIRWAN, G. 2019. Handbook of the Birds of the World Alive. Lynx Edicions, Barcelona. Disponível em: <http://www.hbw.com/>. Acesso em 12 jun. 2019.

DIESEL, A.; BALDEZ, A.; MARTINS, S. Os princípios das metodologias ativas de ensino: uma abordagem teórica. Revista Thema. Instituto Federal de Educação, Ciência e Tecnologia Sul-Rio-Grandense. [s.I.], v. 14, n. 1, p. 268288, 23 fev. 2017.

Encyclopedia of Life. Disponível em:<http://eol.org>. Acesso em: 12 jun. 2019.

ESPINOSA, M. P. P. Análisis Imágenes em Textos Escolares. Pixel Bit: Revista de Médios y Educación, Sevilla, n. 6, 1996.

FERREIRA, A.; UTSUMI, A. G. Utilização de jogos na educação ambiental: uma abordagem prática, XIV Encontro Nacional de Estudantes de Engenharia Ambiental, Blucher Engineering Proceedings, v. 3, 2016, p. 1240-1246..

FONSECA, G. A. B.; RYLANDS, A. B.; PINTO, L. P. S. Estratégia nacional de diversidade biológica: contribuição para a estratégia de conservação in-situ no Brasil. Texto preliminar. Base de Dados Tropical, Campinas-SP, 1999.

FONSECA, G. A. B. da; PINTO, L. P.; RYLANDS, A. B. Biodiversidade e unidades de conservação. Anais do I Congresso Brasileiro de Unidades de Conservação, Conferências e Palestras. p. 189-209. 1997.

FORTUNA, T. R. Jogo em aula. Revista do Professor, Porto Alegre, v. 19, n. 75, p. 15-19, 2003.

FREIRE, P. Pedagogia da autonomia: saberes necessários à prática educativa. 25 ed. São Paulo: Paz e Terra, 1996.

GALETTI, M. Indians within Conservation Units: Lessons from the Atlantic Forest. Conservation Biology, [s.I.], v. 15, n. 3, p. 798-799, jun. 2001.

GARDNER, $\mathrm{H}$. Frames of mind: The theory of multiple intelligences. New York, Ny: Basic Books, 1993.

GOMES, R. R.. FRIEDRICH, M. A. Contribuição dos jogos didáticos na aprendizagem de conteúdos de Ciências e Biologia. Erebio, v. 1, p. 389-92, 2001.

HOBSBAUM, A., PETERS, S., SYLVA, K. Scaffolding in Reading Recovery. Oxford Review Of Education, Informa UK Limited. [s.I.], v. 22, n. 1, p. 17-35, mar. 1996.

IUCN 2019. The IUCN Red List of Threatened Species. Versão 2019-1. Disponível em: <http://www.iucnredlist.org>. Acesso em: 12 jun. 2019. 
KELLERT, S. R.. Birdwatching in American Society. Leisure Sciences, Informa UK Limited. [s.I.], v. 7, n. 3, p.343-360, jan. 1985.

KISHIMOTO, T. M. Jogo, brinquedo, brincadeira e a educação. São Paulo: Cortez editora, 2017.

LITIRELL, M. A., et al. Souvenirs and Tourism Styles. Journal Of Travel Research, SAGE Publications. [s.I.], v. 33, n. 1, p.3-11, jul. 1994

LOVEJOY, T. E. Protected areas: a prism for a changing world. Trends In Ecology \& Evolution, Elsevier BV. [s.I.], v. 21, n. 6, p.329-333, jun. 2006.

LUCKESI, C. C. Tendências pedagógicas na prática escolar. In: LUCKESI, Cipriano Carlos. Filosofia da educação. São Paulo: Cortez, Cap. 3. p. 71-97. 2005.

MALAQUIAS, J. da F. et al. O lúdico como promoção do aprendizado através dos jogos socioambientais, integrando a educação ambiental formal e não formal. Rev. Eletrônica Mestr. Educ. Ambient., v. 29, 2012.

MARINI, M. A.; GARCIA, F. I. Conservação de aves no Brasil. Megadiversidade, v. 1, n. 1, p. 95-102, 2005.

MAYER, M., et al. The economic impact of tourism in six German national parks. Landscape And Urban Planning, Elsevier BV. [s.I.], v. 97, n. 2, p. 7382, ago. 2010.

MENQ, W. - Aves de Rapina Brasil. Disponível em: $<$ http://www.avesderapinabrasil.com/chondrohierax uncinatus.htm>. Acesso em: 12 jun. 2019.

NEVES, M. A. das et al. Influência dos jogos como atividades lúdicas no curso de formação de professores em Química do IFMA. Anais do Encontro Nacional de Ensino de Química (XV ENEQ), 15, 2010, Brasília: Divisão de Ensino de Química da Sociedade Brasileira de Química - Ed/sbq., p. 1 - 11. 2010.

NORMAN, R. S. de S.; SEVERIANO, J. dos S. Educação Ambiental e aves da Caatinga: a construção do conhecimento através de atividades práticas. Revista Brasileira de Educação Ambiental, v.13, n. 3, 42-57, 2018.

PADUA, S. M., TABANEZ, M. F.; SOUZA, M. G. A abordagem participativa na educação para a conservação da natureza, In: CULLEN-JR, L.;, RUDRAN, R.; PÁDUA, C. V.(orgs.). Métodos de Estudo em Biologia da Conservação e da Vida Silvestre. Curitiba: Editora UFPR, 2003, p. 557-591.

PATRIARCHA-GRACIOLLI, S. R.; ZANON, A. M.; SOUZA, P. R. de. “Jogo dos predadores": uma proposta lúdica para favorecer a aprendizagem em ensino de ciências e educação ambiental. REMEA-Revista Eletrônica do Mestrado em Educação Ambiental, v. 20, 2008.

PEREIRA, N. B. Perspectivas para o ensino de Zoologia e os possíveis rumos para uma prática diferente do tradicional, 2012. 43 f. Trabalho de Conclusão de Curso (Licenciatura em Ciências Biológicas)- Universidade Presbiteriana Mackenzie, São Paulo, 2012. 
PIACENTINI, V. et al. Annotated checklist of the birds of Brazil by the Brazilian Ornithological Records Committee/ Lista comentada das aves do Brasil pelo Comitê Brasileiro de Registros Ornitológicos. Revista Brasileira de Ornitologia, Belém, v. 23, n. 2, p. 91-298, jun. 2015.

RESCHKE, M. J. D., PAULETTO, E. M. K. Brinquedoteca: Espaço lúdicocientífico desafios e possibilidades na formação de professores. Anais do III Simpósio Internacional e VI Fórum nacional de Educação, 2009. Torres, RS. Anais. Torres, RS: UERGS, 2009.

RESNICK, M. Give P'sa chance: Projects, peers, passion, play. In: Constructionism and creativity: Proceedings of the Third International Constructionism Conference. Austrian Computer Society, Vienna. p. 13-20. 2014.

RIBEIRO, I. C. Padrões reprodutivos da avifauna em uma área verde planejada do município de Vitória, Espírito Santo, Brasil. Trabalho de Conclusão de Curso (Bacharelado em Ciências Biológicas)-. Universidade Federal do Espírito Santo, Vitória, 2011.

SANTOS, W. L. P. dos. Educação Científica na perspectiva de letramento como prática social: funções, princípios e desafios. Revista Brasileira de Educação, Rio de Janeiro, v. 12, n. 36, p.474-492, set. 2007.

SILVERTOWN, J. A new dawn for citizen Science. Trends in Ecology \& Evolution, Elsevier BV. [s.I.], v.24, n.9, p. 467-471, set. 2009. http://dx.doi.org/10.1016/j.tree.2009.03.017.

SOUZA, J. V. C. de. Congressos Mundiais de Parques Nacionais da UICN (1962-2003): registros e reflexões sobre o surgimento de um novo paradigma para a conservação da natureza. Dissertação (Mestrado)-. Programa de PósGraduação em Desenvolvimento Sustentável, Universidade de Brasília, Brasília. 2013.

STOFFLET, R. T. Putting Constructivist Teaching into Practice in Undergraduate Introductory Science. Eletronic Journal of Science Education, Fort Worth, TX, Texas Christian University, v.3, n. 2, 1999.

SULLIVAN, B. L. et al. EBird: A citizen-based bird observation network in the biological sciences. Biological Conservation, Elsevier BV. [s.I.], v. 142, n. 10, p. 2282-2292, out. 2009.

SIQUEIRA, I. de J.; ANTUNES, A. M. Jogo de trilha "Lixo Urbano": educação ambiental para sensibilização da comunidade escolar. Ensino, Saúde e Ambiente Backup, v. 6, n. 3, 2013.

WIKIAVES. Disponível em: https://www.wikiaves.com.br/. Acesso em: 12 jun. 2019. 